\title{
Continuum of maternity care among rural women in Ethiopia: does place and frequency of antenatal care visit matter?
}

Tegene Legese Dadi ${ }^{1,2^{*}} \mathbb{D}$, Girmay Medhin ${ }^{2,3}$, Habtamu Kebebe Kasaye ${ }^{4}$, Getnet Mitike Kassie ${ }^{5}$, Mulusew Gerbaba Jebena ${ }^{6}$, Wasihun Adualem Gobezie ${ }^{2,7}$, Yibeltal Kiflie Alemayehu ${ }^{2,6}$ and Alula Meresa Teklu²

\begin{abstract}
Introduction: The ministry of health $(\mathrm{MOH})$ of Ethiopia recommends 4 or more focused antenatal care (ANC) visits at health centre (HC) or at a higher level of health facility (HF). In Ethiopia, few studies investigated time dimension of maternal health continuum of care but lack data regarding place dimension and its effect on continuum of care. The aim of this study is to estimate effect of place of ANC-1 visit and adherence to MOH's recommendations of MOH for ANC visits on continuum of care rural in Ethiopia.

Methods: We used data collected from 1431 eligible women included in the National Health Extension Program (HEP) assessment survey that covered 6324 households from 62 woredas in nine regions. The main outcome variable is continuum of care (CoC), which is the uptake of all recommended ANC visits, institutional delivery and postnatal care services. Following descriptive analysis, Propensity Score Matching was used to estimate the effect of place of ANC-1 visit on completion of CoC. Zero inflated Poisson regression was used to model the effect of adherence to $\mathrm{MOH}$ recommendation of ANC visits on intensity of maternal health continuum of care.
\end{abstract}

Result: Only $13.9 \%$ of eligible women completed the continuum of care, and place of first antenatal care (ANC) visit was not significantly associated with the completion of continuum of care $(\beta=0.04,95 \% \mathrm{Cl}=-0.02,0.09)$. Adherence of ANC visit to the $\mathrm{MOH}$ recommendation (at least 4 ANC visits at higher HFs than health posts (HPs)) increased the likelihood of higher intensity of continuum of care (alRR $=1.29,95 \% \mathrm{Cl}: 1.26,1.33)$. Moreover, the intensity of continuum of care was positively associated with being in agrarian areas (alRR $=1.17,95 \% \mathrm{Cl}: 1.06,1.29$ ), exposed to $\operatorname{HEP}(\operatorname{IRR}=1.22,95 \% \mathrm{Cl}: 1.16,1.28)$, being informed about danger signs ( $\mathrm{alRR}=1.14,95 \% \mathrm{Cl}: 1.11,1.18)$ and delivery of second youngest child at HF (IRR $=1.16,95 \% \mathrm{Cl}: 1.13,1.20)$. Increasing age of women was negatively associated with use of services (IRR $=0.90,95 \% \mathrm{Cl}: 0.87,0.94)$.

Conclusion: Completion of maternal health continuum of care is very low in Ethiopia, however most of the women use at least one of the services. Completion of continuum of care was not affected by place of first ANC visit. Adherence to $\mathrm{MOH}$ recommendation of ANC visit increased the intensity of continuum of care. Intensity of continuum of care was positively associated with residing in agrarian areas, HEP exposure, danger sign told, delivery of second youngest child at health facility. To boost the uptake of all maternal health services, it is crucial to work on quality of

*Correspondence: tege2004@gmail.com

${ }^{1}$ College of Medicine \& Health Science, School of Public Health, Hawassa University, Hawassa, Ethiopia

Full list of author information is available at the end of the article permits use, sharing, adaptation, distribution and reproduction in any medium or format, as long as you give appropriate credit to the original author(s) and the source, provide a link to the Creative Commons licence, and indicate if changes were made. The images or other third party material in this article are included in the article's Creative Commons licence, unless indicated otherwise in a credit line to the material. If material is not included in the article's Creative Commons licence and your intended use is not permitted by statutory regulation or exceeds the permitted use, you will need to obtain permission directly from the copyright holder. To view a copy of this licence, visit http://creativecommons.org/licenses/by/4.0/. The Creative Commons Public Domain Dedication waiver (http://creativeco mmons.org/publicdomain/zero/1.0/) applies to the data made available in this article, unless otherwise stated in a credit line to the data. 
health facilities, upgrading the infrastructures of HPs and promoting adherence to $\mathrm{MOH}$ recommendations of ANC visit.

\section{Plain language summary}

Maternal health continuum of care is an integrated service delivery of antenatal care, facility delivery and postnatal care on appropriate time and place. Continuum of care averts more maternal mortality than individual service provision. In Ethiopia a small percent of women complete continuum of care. Previous studies in Ethiopia explored the effect of time on CoC, however the effect of place of service delivery on subsequent continuum of care were not addressed. This study, therefore, assessed the effect of place of service delivery on completion of subsequent continuum of care using data from 1431 fixed cohort of women during the National HEP assessment survey.

The proportion of women who took all essential maternal health services was very low. Whether first antenatal care is at health post or at health centre did not have a significant effect on the completion of maternal health continuum of care. Adherence to the existing recommendations of Ministry of Health for antenatal care visit increases the uptake of maternal health continuum of care. Better completion of maternal health services was observed in agrarian than pastoralist areas, among those who have exposure to health extension program, who have information about danger signs, and who deliver their previous child at health facility. We can conclude that good implementation of the health extension program, and improving service quality at health facilities increase the uptakes of maternal health service. Moreover, promoting adherence of women to the ministry of health ANC recommendations increase uptakes.

Keywords: Maternal health services, Intensity of continuum of care, Health Extension Program, Place of first ANC visit, ANC visit as per $\mathrm{MOH}$ recommendation, Health post

\section{Introduction}

Globally, improving the lives of mothers has been an important public health and development agenda [1] mainly because of three reasons: firstly, it is a means to minimise the disparity of maternal mortality between developed and developing countries by improving the existing situation in developing countries [2]; secondly, it enables women to lead fulfilling and productive lives by providing support during the pregnancy and postpartum periods [3]; thirdly, improved uptake of maternal health services help to reduce maternal and child morbidity and mortality. Maternal death is associated with increased risk of child death, and negatively impacted economic development [3-5]. World Health Organization (WHO) put a global target to reduce Maternal Mortality Ratio (MMR) to less than 70/100,000 live births (LBs) by 2030 [6]. Accordingly, the Ethiopian government has set a target to reduce it to $199 / 100,000$ LBs by the end of 2020 and 42/100,000 LBs by the end of 2035 through provision of improved maternal health services $[7,8]$.

Antenatal care (ANC) service during pregnancy, skilled birth attendant (SBA) during delivery, and postnatal care (PNC) service during postpartum period are the major components of maternal health services [9]. The provision of those services as a continuum has been promoted at a global level to improve maternal and child health which in turn reduces morbidities and the death toll occurring every year $[9,10]$. Continuum of care $(\mathrm{CoC})$ is defined as integrated service delivery of the above-mentioned services for mothers and children on appropriate time and place $[11,12]$.

$\mathrm{CoC}$ has two important dimensions: the time of care delivery (i.e. from pregnancy to postpartum period), and place of service delivery or level of care delivery $[12,13]$. Most of maternal and neonatal deaths occur during the time of delivery and immediate postpartum, when the services are not given in the appropriate health facilities or if it is provided in a poorly equipped health facilities. Most maternal death in Ethiopia occurs at home during postpartum period, which is shoved up by high home delivery $[14,15]$. CoC can avert $71 \%$ of MMR but reduced to $37 \%$ if one of the services is missing from the continuum $[16,17]$.

Even though $\mathrm{CoC}$ is a core principle and framework to save the lives of mothers and babies, there is high drop out of mothers in the continuum as we go from ANC to PNC in Ethiopia [18, 19]. Despite the high proportion (74.0\%) of ANC-I attendance in Ethiopia, only $43.0 \%$ of women received ANC-4+, $48 \%$ of women delivered at health facility and only $34 \%$ of women received a PNC check-up [19]. In other studies in Ethiopia only 9-12\% of women completed continuum of care [20,21]. Even though health centers, health posts and hospitals have different standards in terms of infrastructure and equipment, Health centers and health posts have low maternal health service readiness compared to hospitals due to lack of competent professionals, lack of essential equipment, supplies, and infrastructure [22-24]. This compromised 
quality of facilities is among the factors that deter women from completion of $\mathrm{CoC}$ [25]. The Ethiopian ministry of health $(\mathrm{MOH})$ recommends to have 4 or more ANC visits at the health centre or at a higher level health facility. Although the $\mathrm{MOH}$ recommends health posts not to provide focused ANC [26], almost one third of women attend their ANC at the health post [27].

Some of Ethiopian studies investigated time dimension of maternal health continuum of care but lack data regarding place dimension of the $\mathrm{CoC}[20,28]$. There is paucity of evidence that shows effect of place and frequency of ANC visits as per the recommendations of $\mathrm{MOH}$ on subsequent continuum of care. The findings from this study will have significant policy implications to improve maternal health service utilization in Ethiopia and similar settings. The aim of this study is to estimate effect of place of ANC-1 visit and adherence to the recommendations of $\mathrm{MOH}$ for $\mathrm{ANC}$ visit on $\mathrm{CoC}$ using data collected from a fixed cohort of women in Ethiopia using data from the National Health Extension Program assessment [29].

\section{Methods}

\section{Study setting and context}

Ethiopia is located in the Eastern part of Africa, which is administratively divided into five agrarian (agriculture as the main way of living) regions, two pastoralist (livestock raising as the main way of living), two regions with both agrarian and pastoralist areas, and two City administration at time of data collection. Each region was further administratively divided into zones, then into woredas, and finally into kebeles. Kebeles are the lowest government administrative unit and it has an average household size of $500-1000$ and a population of $2500-5000$. The country has an estimated 100.8 million population of which four-fifth of the population resides in rural settings, with a 4.7 average family size, and a $2.6 \%$ average annual population growth rate. Females constitute around $49.8 \%$ of the national population and half of these females are within the reproductive age [30].

Maternal health services are delivered in a three-tier health system that includes primary, secondary, and tertiary levels. At the primary level of health service delivery there are health posts staffed with Health Extension Workers (HEWs), health centers staffed with nurses and health officers, and primary hospitals. The health extension program encompasses health posts (HPs) and HEWs, and it is the main service delivery modality at the primary level for the community [31].

\section{Data source and its descriptions}

We used data from the National HEP assessment survey which field data collection was conducted from March to
May 2019. The rural component of the survey covered 62 woreda distributed across all the 9 agrarian and pastoralist regions using multistage sampling design. Three kebeles per woreda, and 34 households ( $\mathrm{HHs}$ ) per kebele were randomly selected. A total of $6324 \mathrm{HHs}$ were recruited from 185 kebeles for the survey. Thus the data is collected from health posts and HHs from the selected kebeles. The respondents for the $\mathrm{HH}$ survey were women and their husbands, and HEWs for health post survey [29].

\section{Sample size}

The study population includes women of reproductive age (15-49 years) who delivered a child in the last two years. The study included 1431 women from $6324 \mathrm{HHs}$ who were part of a fixed cohort from antenatal to postnatal care and the catchment health posts in the selected kebeles. The selected women were asked about their use of maternal health services for their last delivery in the last two years. The health post assessment includes service availability, equipment and human resource characteristics.

\section{Measurements}

\section{Outcome of interest}

Two outcome of interest were analysed in this paper:

1. Completion of Continuum of care $(\mathrm{CoC})$ : It is defined by the completion of all recommended ANC visits (at least 4 ANC), institutional delivery (ID) and PNC services. A woman is said to have completed $\mathrm{CoC}$, coded as " 1 ", if she received all mentioned services, and incomplete $\mathrm{CoC}$, coded as " 0 ", if she missed at least one of the recommended services. This outcome was used to see effect of place of first ANC visit on continuum of care

2. Intensity of Continuum of care: A woman may have a score of 0-6 based on service uptake of ANC-I to ANC-IV, ID and PNC. If a woman utilized all of the services the score is 6 , if she did not get any service she gets the score of 0 . This outcome was used to investigate effect of ministry of health $(\mathrm{MOH})$ recommendations of ANC visit on continuum of care.

\section{Exposure variables}

There are two main exposure variables.

1. Place of ANC-1 visit: if the ANC-1 visit was at health post (HP) it is coded as " 0 " and if it was at health centre (HC) or other higher health facilities (HFs) it was coded as " 1 ". It will be used to explain completion of continuum of care. 
2. ANC visit as per the recommendation of $\mathrm{MOH}$ : defined based on 4 or more ANC visits at $\mathrm{HC}$ or other higher HFs other than HPs. If a woman has 4 or more ANC visits at $\mathrm{HC}$ or other higher HFs, it is coded as "Recommended place and frequency," and if one of the criteria is not fulfilled, it is marked as "Not recommended place and frequency." [26]. It will be used to explain intensity of continuum of care.

\section{Other covariates}

These variables include individual, household, and kebele level factors. Individual level factors include: age, marital status, whether she is a household head or not, family size, maternal and paternal education (whether the mother or husband attended grade one or more education coded as formal education), if she has exposure to HEP (Yes response if a woman took any services at a HP or if she is visited by a HEWs at her home, and No response if she is not visited anywhere), having access to media, awareness of husband and wife about MHS (ANC, ID and PNC) availability, if she was told about danger sign, and place of delivery for the previous child. Household level factors included: wealth index which is categorized into three groups (high, medium and low). The kebele level variables are the number of medical equipment at HP (a continues variable ranging from 0 to 11 which measures the availability of 11 essential medical equipment at the HP like different guidelines, statoscope, BP apparatus ...), and human resource at HP which is categorized as "Presence of at most level-3 HEWs" if HPs have level 3 or below HEWs and "Presence of at least level-4 HEWs" if the HPs have at least level 4 HEWs.
Access to health facility it is categorized as "Accessed HP/HEW" if the women have a nearby HP or HEW for use and "Accessed other HF" if the women have a nearby health centre or other higher level health facility.

\section{Conceptual framework}

We have adapted the social ecological model since the model considers the complex interplay of multiple levels factors and interactions between individuals, household and kebele or health post level factors [32], which will affect the utilization of maternal health service in the continuum (Fig. 1).

\section{Data management and analysis}

We cleaned and analysed the data using Stata version 16.1. We did weighed analysis to account for disproportionate stratification of number of different regions, use of multistage sampling to recruit study participants and to be able to generalize the finding to the national reference population. Wealth quintiles were used as a proxy measure of socio-economic status. Descriptive analysis including frequencies, crosstabulations, and graphical presentations were used to summarize characteristics of study participants across different characteristics. We used Propensity Score Matching (PSM) analysis, which is one of the treatment effect model in stata, to estimate the effect of place of ANC-1 visit on the completion of $\mathrm{CoC}$ which is the binary response. We used Zero inflated Poisson (ZIP) regression to model the effect of adherence to $\mathrm{MOH}$ recommendation of ANC visits on intensity of maternal health continuum of care that has values ranging from 0 to 6 . The model is selected after checking the validity of required

\section{Kebele or health post level factors}

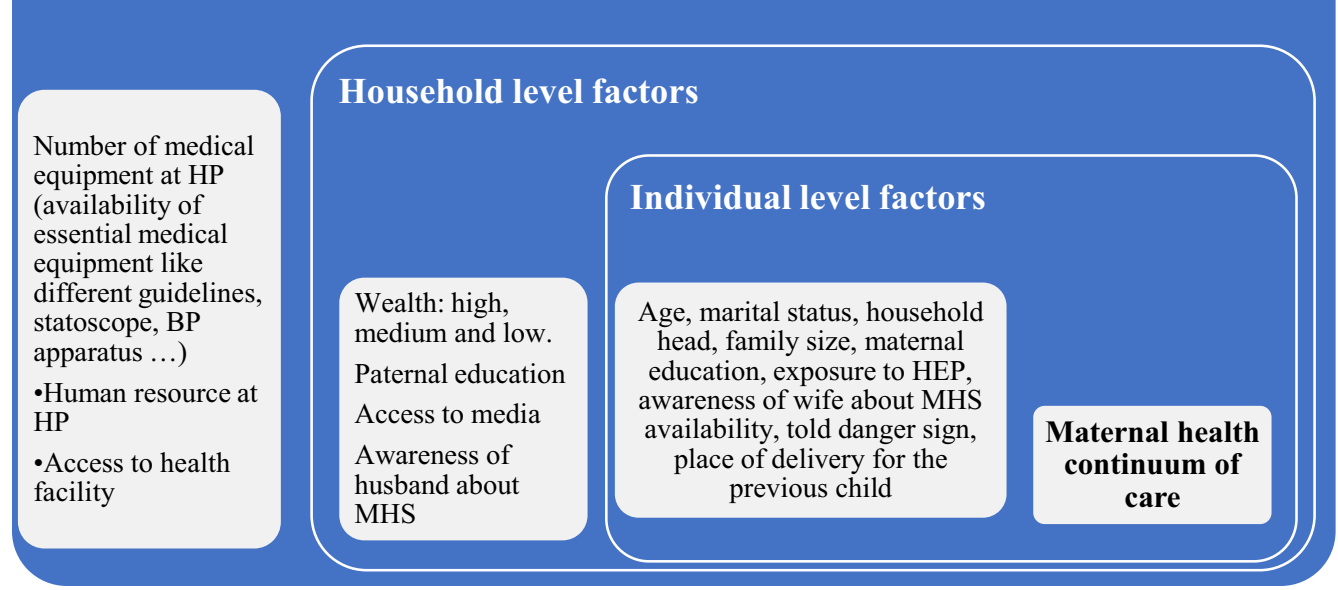

Fig. 1 The conceptual framework showing the multilevel factors affecting maternal health continuum of care 
assumptions [33]. The exposure variable (adherence to $\mathrm{MOH}$ recommendation) has some degree of overlap with the outcome variable, intensity of $\mathrm{CoC}$. We have conducted re-analysis of the model after removal of the overlap. We reported the findings as statistical significant whenever p-value was less than $5 \%$.

\section{Result}

\section{Characteristics of study participants}

This finding is based on data collected from a total of 1431 fixed cohort of women. Their mean age was 28.6 years $(\mathrm{SD}=6.39$, minimum age $=16$ years, and maximum age $=48$ years), $4 \%$ of the participants were from pastoralist areas, majority do not have formal

Table 1 Socio-economic characteristics of study participants

\begin{tabular}{lll}
\hline Characteristics of study & $\begin{array}{l}\text { Unweighted } \\
\text { number } \\
(n=1431)\end{array}$ & Weighted \% \\
participants &
\end{tabular}

\begin{tabular}{|c|c|c|}
\hline \multicolumn{3}{|l|}{ Women education } \\
\hline No formal education & 947 & 58.96 \\
\hline Formal education & 484 & 41.04 \\
\hline \multicolumn{3}{|c|}{ Husband education $(n=1184)$} \\
\hline No formal education & 561 & 38.67 \\
\hline Formal education & 623 & 61.33 \\
\hline \multicolumn{3}{|l|}{ Marital status } \\
\hline Currently married & 1342 & 96.36 \\
\hline Others & 89 & 3.64 \\
\hline \multicolumn{3}{|l|}{ Livelihood } \\
\hline Women in Pastoralist & 422 & 3.98 \\
\hline Women in Agrarian & 1009 & 96.02 \\
\hline \multicolumn{3}{|l|}{ Family size } \\
\hline Up to 4 peoples & 437 & 33.31 \\
\hline 5-8 peoples & 854 & 55.2 \\
\hline 9 or more peoples & 140 & 11.49 \\
\hline \multicolumn{3}{|l|}{ Wealth index } \\
\hline Lower quintile & 407 & 25.51 \\
\hline Middle quintile & 478 & 32.68 \\
\hline Higher quintile & 546 & 41.81 \\
\hline \multicolumn{3}{|l|}{ Head of $\mathrm{HH}$} \\
\hline Male headed HH & 1310 & 94.24 \\
\hline Female headed HH & 121 & 5.76 \\
\hline \multicolumn{3}{|l|}{ Media } \\
\hline Have no TV or Radio & 938 & 57.08 \\
\hline Have TV or Radio & 493 & 42.92 \\
\hline \multicolumn{3}{|c|}{ Accessed health facility in the last one year } \\
\hline Accessed other HF & 152 & 7.42 \\
\hline Accessed HP/HEW & 1279 & 92.58 \\
\hline
\end{tabular}

$H H s$ Households, $T V$ television, HF health facility, HP health post, HEW health extension worker education and $5.8 \%$ of the $\mathrm{HHs}$ were female headed (Table 1).

\section{Exposure to HEP and awareness about service availability at HP}

The mean availability score of medical equipment was $7.98 \quad(\mathrm{SD}=2.98$, minimum number $=0$, and maximum $=14$ ) and $1.44 \%$ of the HPs do not have any medical equipment. More than $80 \%$ of the women had exposure to HEP, availability of delivery service at the HP was least known by the women and their husbands, and the commonest known service at HP was ANC. More than 73\% of HPs have at least one level IV HEWs (Table 2).

More than half of (55.5\%) the women were not told at least one danger sign on their previous pregnancy and two third (64\%) of women delivered their second youngest child at home (data not shown).

\section{Maternal health services uptake}

Maternal health service uptake decreases as they progress from ANC-I to PNC. For example most of the

Table 2 Exposure to HEP and service awareness about service availability at HP

\begin{tabular}{|c|c|c|}
\hline $\begin{array}{l}\text { Characteristics of study } \\
\text { participants }\end{array}$ & $\begin{array}{l}\text { Unweighted } \\
\text { number } \\
(n=1431)\end{array}$ & Weighted \% \\
\hline \multicolumn{3}{|l|}{ HEP exposure } \\
\hline No & 332 & 18.97 \\
\hline Yes & 1099 & 81.03 \\
\hline \multicolumn{3}{|l|}{ ANC service awareness at HP } \\
\hline Both (husband \& wife) are not aware & 279 & 10.98 \\
\hline At least one of them aware & 414 & 24.66 \\
\hline Both (Husband \& wife) are aware & 738 & 64.35 \\
\hline \multicolumn{3}{|l|}{ Delivery service awareness at HP } \\
\hline Both (Husband \& wife) are not aware & 747 & 44.41 \\
\hline At least one of them aware & 331 & 21.73 \\
\hline Both (Husband \& wife) are aware & 353 & 33.87 \\
\hline \multicolumn{3}{|l|}{ PNC service awareness at HP } \\
\hline Both (Husband \& wife) are not aware & 546 & 33.27 \\
\hline At least one of them aware & 405 & 25.8 \\
\hline Both (Husband \& wife) are aware & 480 & 40.92 \\
\hline \multicolumn{3}{|c|}{ MHS (ANC, Delivery \& PNC) awareness by husband and wife at HP } \\
\hline Both are not aware for all MHS & 242 & 8.88 \\
\hline At least one of them aware & 888 & 62.21 \\
\hline Both are aware for all MHS & 301 & 28.92 \\
\hline \multicolumn{3}{|l|}{ Human resource at the HP } \\
\hline Have level 3 or below HEWs & 526 & 26.88 \\
\hline Have at least one level 4 HEWs & 727 & 73.12 \\
\hline
\end{tabular}

HEP health extension program, HP health post, $A N C$ antenatal care, $P N C$ postnatal care, MHS maternal health services, HEW health extension worker, HEWs health extension worker 


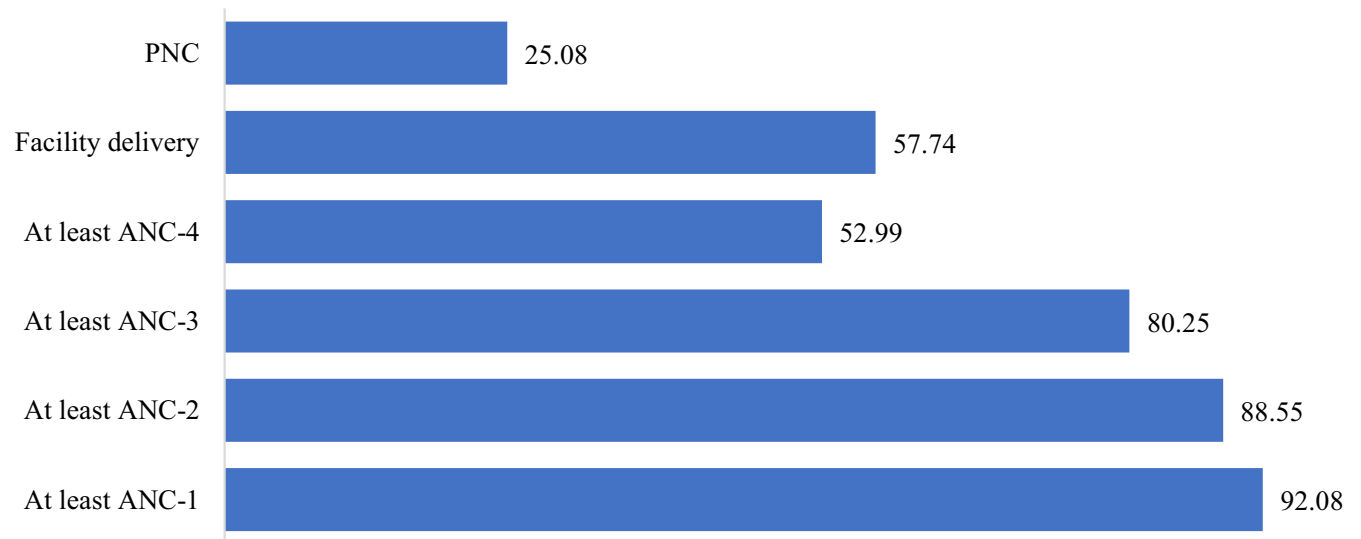

Fig. 2 Maternal health service uptake among fixed cohort of women in Ethiopia

women (92\%) took at least one ANC visit, but only $25 \%$ took PNC (Fig. 2).

Among the study participant women, $47 \%$ took their ANC-I at HP and the rest took the services at $\mathrm{HC}$ or other higher level HFs. Around three fourth (73.90\%) of the women didn't take all ANC visits based on the recommendation of $\mathrm{MOH}$ and only $26.10 \%$ have recommended number and place of ANC visits (Fig. 3).

\section{Place and adherence to $\mathrm{MOH}$ recommendation of ANC visits, and maternal health $\mathrm{CoC}$}

Among women who have at least ANC-1, 14.8\% completed $\mathrm{CoC}$ with no significant difference among women who took their ANC-1 at HP and those who took at $\mathrm{HC}$ or other HFs (Fig. 4).

There is high drop out of women receiving maternal health services as we go along in the continuum of care.
Only $13.88 \%$ of the cohort completed the continuum of care, $6.6 \%$ of them received $\mathrm{MOH}$ recommended ANC visits, $6.5 \%$ of women didn't take any one of the services (Fig. 5).

\section{Effect of place of ANC-1 visit on continuum of care}

The result of PSM showed that place of ANC-1 visit does not have a significant effect on the completion of continuum of care $(\beta=0.04,95 \% \mathrm{CI}=-0.02,0.09)$ after adjusting for covariates. The model was adjusted for age, women education, livelihood, family size, wealth index, gender of $\mathrm{HH}$ head, exposure to HEP, MHS service awareness by wife and husband, whether she was informed or not about danger sign during ANC visit, status of facility delivery of second youngest child, presence of medical equipment in the HP,

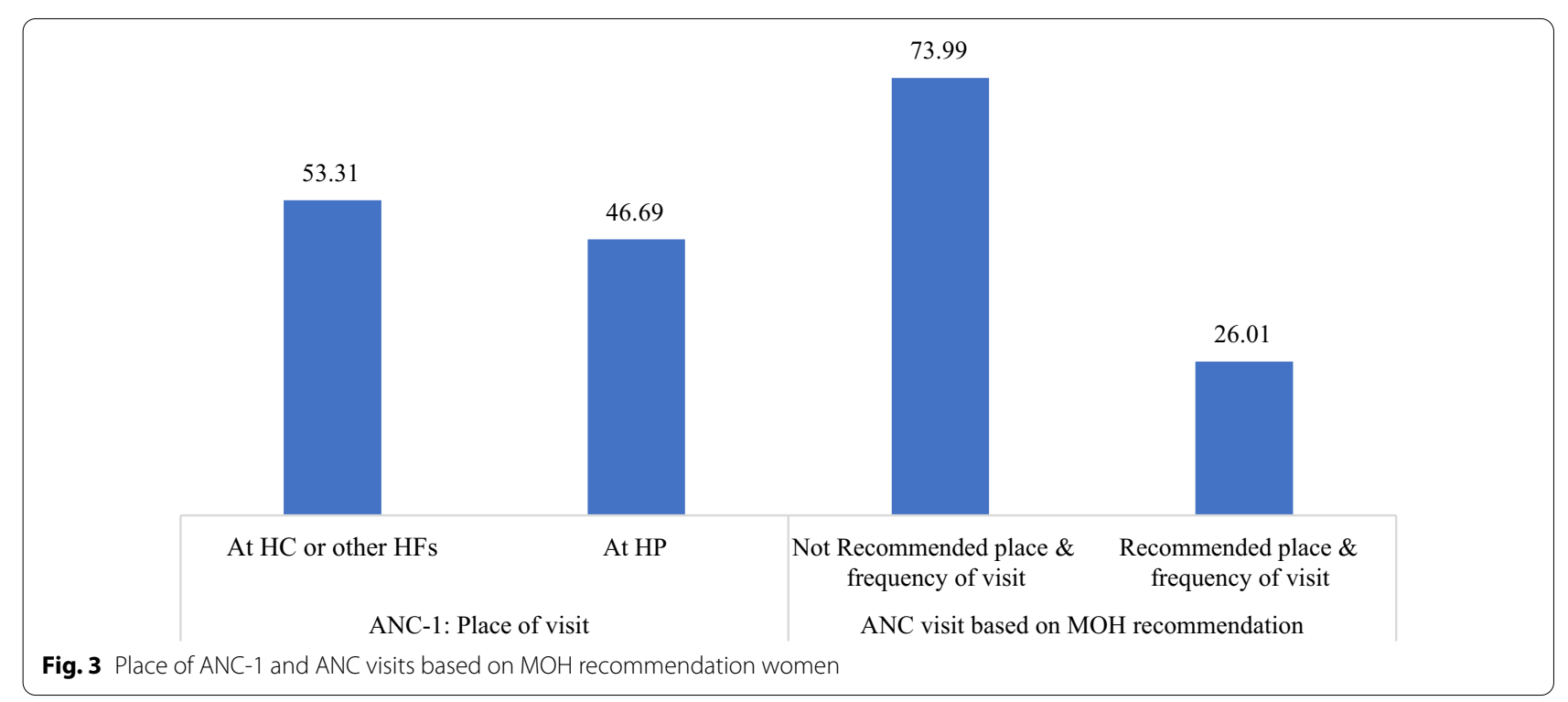


- ANC-1: At HP

ANC-1: At HC or other HF

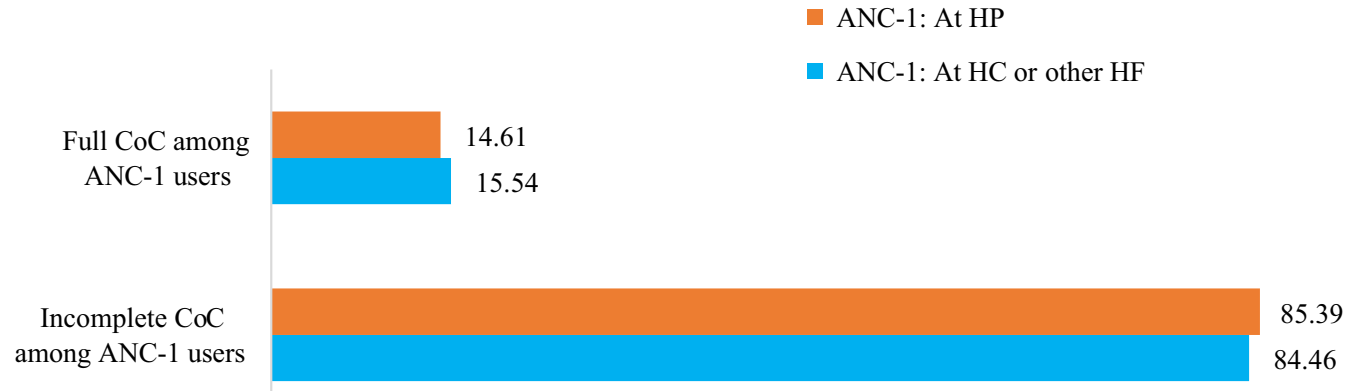

Fig. 4 Completion of $\mathrm{CoC}$ among women who took their ANC-1 at HP and HC or other higher HFs

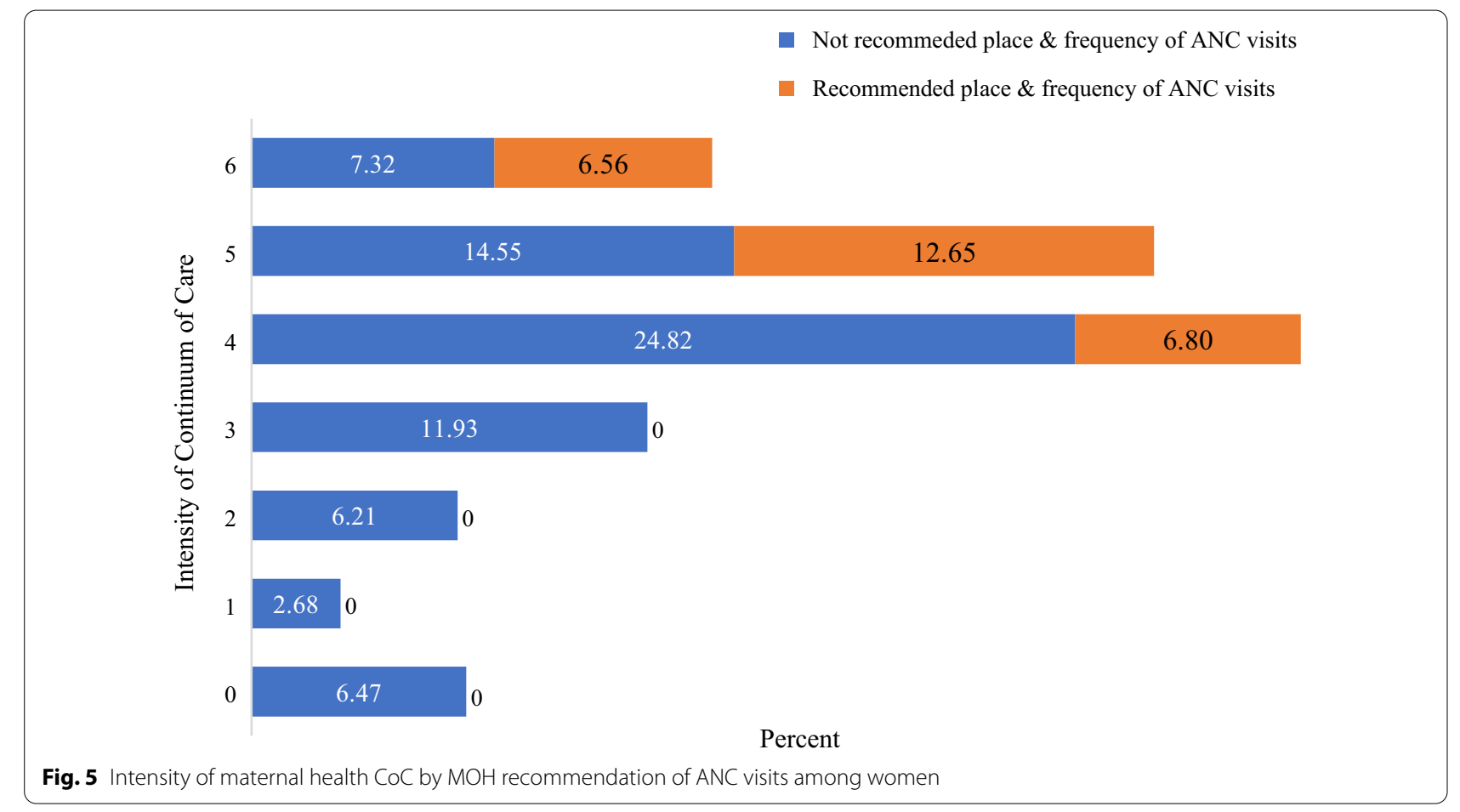

status of access to HP, human resource of HP, paternal formal education and media (table not shown).

\section{The effect of adherence to $\mathrm{MOH}$ recommendation of ANC visit on intensity of $\mathrm{CoC}$}

Adherence to $\mathrm{MOH}$ recommendation of ANC visit was consistently associated with increased intensity of $\mathrm{CoC}$ or increased uptake of $\mathrm{CoC}$ across all hypothesis testing models. In the fully adjusted model it increases the incidence of uptake of continuum of care by 1.28 times $($ aIRR $=1.28,95 \%$ CI: $1.24,1.32)($ Table 3$)$.
Table 3 A hypothesis testing that shows effect of $\mathrm{MOH}$ Recommended ANC visits on CoC among women

\begin{tabular}{ll}
\hline Effect of ANC visit based on $\mathbf{M O H}$ recommendation & IRR $(\mathbf{9 5 \%} \mathbf{C l})$ \\
\hline $\begin{array}{l}\text { Crude effect of ANC visit based on } \mathrm{MOH} \text { recommenda- } \\
\text { tion }\end{array}$ & $1.29(1.26,1.33)$ \\
${ }^{*}$ Adjusted effect of ANC visit based on $\mathrm{MOH}$ recom- & $1.28(1.24,1.32)$ \\
mendation &
\end{tabular}

*Adjusted for: exposure status to HEP, maternal age, women formal education, MHS service awareness by wife and husband, danger sign told, facility delivery of second youngest child, wealth index, family size, wife headed $\mathrm{HH}$, livelihood, number of medical equipment, accessed $\mathrm{HP}$, human resource of $\mathrm{HP}$, and media 


\section{Factors affecting intensity of continuum of care}

The intensity of continuum of care increases with exposure to HEP (aIRR $=1.22$, 95\% CI: 1.16, 1.28), residing in agrarian areas $(\mathrm{aIRR}=1.17,95 \% \mathrm{CI}: 1.06,1.29)$, who heard about danger signs $(\mathrm{aIRR}=1.14,95 \% \mathrm{CI}$ : 1.11 , 1.18) and who deliver their second youngest child at HF $(\mathrm{aIRR}=1.16,95 \%$ CI: 1.13, 1.20) (Table 4).
There is overlap of exposure variable (Adherence to recommendation of $\mathrm{MOH}$ to $\mathrm{ANC}$ ) and intensity of $\mathrm{CoC}$ in terms of frequency of ANC which is included in both. We have re-analyzed the analysis by removing the overlap from the exposure variable. The result showed that there is no difference in the effect of the exposure on the outcome (Table 5).

Table 4 Factors associated with intensity of continuum of care among fixed cohort of women in Ethiopia

\begin{tabular}{|c|c|c|c|}
\hline \multicolumn{2}{|l|}{ Background characteristics } & \multirow{2}{*}{$\begin{array}{l}\text { Crude IRR }(95 \% \mathrm{Cl}) \\
\text { Ref }\end{array}$} & \multirow{2}{*}{$\begin{array}{l}\text { Adjusted IRR }(95 \% \mathrm{Cl}) \\
\text { Ref }\end{array}$} \\
\hline Adherence to recommendation of $\mathrm{MOH}$ to $\mathrm{ANC}$ & No & & \\
\hline & Yes & $1.29(1.26,1.33)$ & $1.28(1.24,1.32)$ \\
\hline \multirow[t]{2}{*}{ Exposure to HEP } & No & Ref & Ref \\
\hline & Yes & $1.11(1.07,1.15)$ & $1.22(1.16,1.28)$ \\
\hline Age & & $1.00(0.99,1.00)$ & $1.01(1.00,1.01)$ \\
\hline \multirow[t]{2}{*}{ Women education } & No formal education & Ref & Ref \\
\hline & Have formal education & $1.09(1.07,1.12)$ & $1.05(1.02,1.08)$ \\
\hline \multirow[t]{3}{*}{ MHS awareness by husband and wife at HP } & Both are not aware for all MHS & Ref & Ref \\
\hline & At least one of them aware & $1.01(0.96,1.05)$ & $1.06(1.00,1.12)$ \\
\hline & Both are aware for all MHS & $0.94(0.89,0.98)$ & $0.96(0.96,1.08)$ \\
\hline \multirow[t]{2}{*}{ Told at least one danger sign } & No & Ref & Ref \\
\hline & Yes & $1.17(1.14,1.19)$ & $1.14(1.11,1.18)$ \\
\hline \multirow[t]{2}{*}{ The second youngest child place of delivery } & Home or other place & Ref & Ref \\
\hline & Health institution & $1.18(1.15,1.22)$ & $1.16(1.13,1.20)$ \\
\hline \multirow[t]{3}{*}{ Wealth index } & Lower quintile & Ref & Ref \\
\hline & Middle quintile & $0.94(0.91,0.97)$ & $0.91(0.88,0.95)$ \\
\hline & Higher quintile & $1.03(1.00,1.06)$ & $0.96(0.92,1.01)$ \\
\hline \multirow[t]{3}{*}{ Family size } & $\leq 4$ peoples & Ref & Ref \\
\hline & 5-8 peoples & $0.97(0.95,0.99)$ & $1.01(0.97,1.05)$ \\
\hline & $\geq 9$ peoples & $0.88(0.84,0.92)$ & $1.02(0.96,1.08)$ \\
\hline \multirow[t]{2}{*}{ Head of $\mathrm{HH}$} & Husband headed $\mathrm{HH}$ & Ref & Ref \\
\hline & Wife headed HH & $1.04(0.98,1.09)$ & $0.97(0.91,1.03)$ \\
\hline Number of medical equipment & & $1.01(1.00,1.01)$ & $1.01(1.01,1.02)$ \\
\hline \multirow[t]{2}{*}{ Media } & Have no TV or Radio & Ref & Ref \\
\hline & Have TV or Radio & $1.06(1.04,1.09)$ & $1.01(0.98,1.05)$ \\
\hline \multirow[t]{2}{*}{ Livelihood } & Pastoralist & Ref & Ref \\
\hline & Agrarian & $1.31(1.19,1.42)$ & $1.17(1.06,1.29)$ \\
\hline \multirow[t]{2}{*}{ Human resource at the HP } & Have level 3 and below HEWs & Ref & Ref \\
\hline & Have at least one level 4 HEW & $0.95(0.93,0.97)$ & $0.93(0.90,0.95)$ \\
\hline \multirow[t]{2}{*}{ Accessed health facility } & Accessed other HF & Ref & Ref \\
\hline & Accessed HP/HEW & $1.13(1.07,1.18)$ & $0.94(0.87,1.01)$ \\
\hline \multicolumn{4}{|l|}{ Inflate variables* } \\
\hline Age & & & $0.90(0.87,0.94)$ \\
\hline \multirow[t]{2}{*}{ Women education } & No formal education & & Ref \\
\hline & Have formal education & & $1.89(2.12,4.73)$ \\
\hline \multirow[t]{2}{*}{ Head of $\mathrm{HH}$} & Husband headed HH & & Ref \\
\hline & Wife headed HH & & $0.84(0.19,3.67)$ \\
\hline
\end{tabular}

$\mathrm{Cl}$ confidence interval, $H H$ Household, HEP health extension program, HP health post, MHS maternal health services; $H F$ health facility, HEW health extension worker, $T V$ television, HEWs health extension worker

*Inflate variables are variables that increases the probability of taking no services. They are selected based on literatures. 
Table 5 Sensitivity analysis of factors associated with intensity of continuum of care among fixed cohort of women in Ethiopia

\begin{tabular}{|c|c|c|c|}
\hline Background characteristics & & Crude IRR (95\% Cl) & Adjusted IRR (95\% Cl) \\
\hline \multirow[t]{2}{*}{ Adherence to recommendation of $\mathrm{MOH}$ to ANC } & No & Ref & Ref \\
\hline & Yes & $1.29(1.26,1.33)$ & $1.25(1.22,1.29)$ \\
\hline \multirow[t]{2}{*}{ Exposure to HEP } & No & Ref & Ref \\
\hline & Yes & $1.11(1.07,1.15)$ & $1.22(1.15,1.28)$ \\
\hline Age & & $1.00(0.99,1.00)$ & $1.04(1.01,1.08)$ \\
\hline \multirow[t]{2}{*}{ Women education } & No formal education & Ref & Ref \\
\hline & Have formal education & $1.09(1.07,1.12)$ & $1.05(1.02,1.08)$ \\
\hline \multirow[t]{3}{*}{ MHS awareness by husband and wife at HP } & Both are not aware for all MHS & Ref & Ref \\
\hline & At least one of them aware & $1.01(0.96,1.05)$ & $1.07(1.01,1.13)$ \\
\hline & Both are aware for all MHS & $1.02(0.89,0.98)$ & $0.96(0.96,1.08)$ \\
\hline \multirow[t]{2}{*}{ Told at least one danger sign } & No & Ref & Ref \\
\hline & Yes & $1.17(1.14,1.19)$ & $1.14(1.11,1.18)$ \\
\hline \multirow[t]{2}{*}{ The second youngest child place of delivery } & Home or other place & Ref & Ref \\
\hline & Health institution & $1.18(1.15,1.22)$ & $1.18(1.15,1.21)$ \\
\hline \multirow[t]{3}{*}{ Wealth index } & Lower quintile & Ref & Ref \\
\hline & Middle quintile & $0.94(0.91,0.97)$ & $0.91(0.88,0.95)$ \\
\hline & Higher quintile & $1.03(1.00,1.06)$ & $0.97(0.93,1.01)$ \\
\hline \multirow[t]{3}{*}{ Family size } & $\leq 4$ peoples & Ref & Ref \\
\hline & 5-8 peoples & $0.97(0.95,0.99)$ & $1.01(0.97,1.05)$ \\
\hline & $\geq 9$ peoples & $0.88(0.84,0.92)$ & $1.01(0.95,1.08)$ \\
\hline \multirow[t]{2}{*}{ Head of $\mathrm{HH}$} & Husband headed $\mathrm{HH}$ & Ref & Ref \\
\hline & Wife headed HH & $1.04(0.98,1.09)$ & $0.96(0.90,1.03)$ \\
\hline Number of medical equipment & & $1.01(1.00,1.01)$ & $1.01(1.01,1.02)$ \\
\hline \multirow[t]{2}{*}{ Media } & Have no TV or Radio & Ref & Ref \\
\hline & Have TV or Radio & $1.06(1.04,1.09)$ & $1.01(0.98,1.05)$ \\
\hline \multirow[t]{2}{*}{ Livelihood } & Pastoralist & Ref & Ref \\
\hline & Agrarian & $1.31(1.19,1.42)$ & $1.19(1.08,1.31)$ \\
\hline \multirow[t]{2}{*}{ Human resource at the HP } & Have level 3 and below HEWs & Ref & Ref \\
\hline & Have at least one level $4 \mathrm{HEW}$ & $0.95(0.93,0.97)$ & $0.94(0.91,0.97)$ \\
\hline \multirow[t]{2}{*}{ Accessed health facility } & Accessed other HF & Ref & Ref \\
\hline & Accessed HP/HEW & $1.13(1.07,1.18)$ & $0.95(0.88,1.02)$ \\
\hline \multicolumn{4}{|l|}{ Inflate variables* } \\
\hline Age & & & $0.90(0.87,0.94)$ \\
\hline \multirow[t]{2}{*}{ Women education } & No formal education & & Ref \\
\hline & Have formal education & & $1.89(2.12,4.73)$ \\
\hline \multirow[t]{2}{*}{ Head of HH } & Husband headed $\mathrm{HH}$ & & Ref \\
\hline & Wife headed HH & & $0.84(0.19,3.67)$ \\
\hline
\end{tabular}

$\mathrm{Cl}$ confidence interval, $H H$ Household, $H E P$ health extension program, $H P$ health post, $M H S$ maternal health services, $H F$ health facility, $H E W$ health extension worker, $T V$ television, HEWs health extension worker

*Inflate variables are variables that increases the probability of taking no services. They are selected based on literatures

\section{Discussion}

Our finding show that there is very high drop out of maternal health service uptake along the continuum. Even though very large proportion of women took at least one of the services, only one in seven women completed the continuum of care. Place of first ANC visit didn't have a significant effect on the completion of CoC. Adhering to $\mathrm{MOH}$ recommendation of $\mathrm{ANC}$ visit increases the uptake of $\mathrm{CoC}$. Intensity of $\mathrm{CoC}$ increases among women who are residing in agrarian areas, who have HEP exposure, who hear about danger sign, and who delivered their second youngest child at HF.

In spite of very large percent of women taking at least one components of $\mathrm{COC}$, small percent of them completed $\mathrm{CoC}$ in agreement with pocket studies in Ethiopia in which only $9.7-12.1 \%$ of women completed continuum 
of care findings [21, 28]. Furthermore, results from 2016 DHS have indicated similar findings [34]. The findings indicate that there is much to be done to improve the uptake. Several factors related to socioeconomic, cultural and health facilities are likely to contribute more to the low completion of continuum of care.

Our result demonstrates that nearly equal proportion of women took their ANC-1 at HP and HC or higher level of facility but, it didn't show difference in completion of $\mathrm{CoC}$ which is in conformity with a study conducted elsewhere in Ethiopia [35]. Those findings are in the contrary to the recommendation of the MOH in two ways: (1) HPs aren't allowed to provide focused ANC due to lack of infrastructure and equipment; (2) HCs or other higher level HFs are expected to have better completion of $\mathrm{CoC}$ due to their better standards $[26,36]$. The lack of difference in completion of $\mathrm{CoC}$ implies that there is compromised quality of care across the health facilities (HFs) because retention in care needs better quality of services. Previous studies affirmed that communities fail to complete the $\mathrm{CoC}$ due to unmet need of services and lack of equipment across HFs $[24,37]$. Thus, compromised quality of care deter the completion of $\mathrm{CoC}$. These findings imply the quality of ANC-1 service, which is the critical entry point of the women, at $\mathrm{HC}$ should be in question.

One in seven women completed maternal health $\mathrm{CoC}$, and only a quarter of women took ANC visits as per the recommendation of $\mathrm{MOH}$ which is very low in contrast to the recommendations $[9,13]$. ANC visits as per the $\mathrm{MOH}$ recommendation consistently increases the likelihood of uptake of $\mathrm{CoC}$ across all hypothesis testing models. Previous studies showed that higher number of ANC visits are associated with increased uptake of MHS [38, 39]. When those contacts are at the recommended type of HFs, it improves the continuity of maternity care [40]. The Ethiopian $\mathrm{MOH}$ recommends to provide ANC-4 at HFs other than HP due to incapability of HPs by the standard to examine pregnancy, treat complications, and attend delivery [26, 41]. These findings tells us that most women are not vising the minimum required number of ANC visits, and they are following at the health posts. This may imply that those women may not have access to higher HFs. Even though increasing number of ANC contacts is important to improve $\mathrm{CoC}$, it is equally important to promote visit at higher health facilities.

This study demonstrated that exposure to HEP increases intensity of continuum of care, which is in conformity with a study conducted in Ethiopia [42]. This shows that HEP is meeting one of its targets that is improving maternal and child health [43]. This implies that a good implementation of HEP through home visit, outreach visit and enhanced quality of HP services improves the $\mathrm{CoC}$. Moreover, women who heard about danger sign and women who delivered their second youngest child at health facility were more likely to have higher intensity of continuum of care. This finding is in line with the findings of previous studies in which women who received health education on maternal healthcare services were more likely to complete the continuum of care $[34,44]$. It is because of a good consultation including reminding on danger signs, and persuade the users to understand their health status increases the attachment of the women with the facility. Thus, providing appropriate care at time of their contact with health facility or health professional has a potential to improve the continuum of care.

Women from agrarian areas receive a higher intensity of $\mathrm{CoC}$ as compared to pastoralist women. As different research shows pastoralism is a conundrum to provide health services, particularly socio-cultural factors, geographic access and service quality of health services are the major bottle necks $[45,46]$. Even though those problems are also found among agrarian areas it is not arduous like in pastoralist areas. This implies that there is inequity in service availability and accessibility among agrarian and pastoralist areas in Ethiopia.

The study has two major strengths. The study conducted from nationally representative sample of $\mathrm{HHs}$ and it includes women from both agrarian and pastoralist regions. Moreover it sees the contribution of HEP. As limitation recall bias might be there in measuring ANC and delivery. Other limitations of the study are other variables such as distance to health facility and quality of care at different health facility which determine the completion of the $\mathrm{CoC}$ were not measured.

\section{Conclusion}

Completion of maternal health continuum of care is very low in Ethiopia, however most of the women use at least one of the services. Place of first ANC visit didn't have significant effect on the completion of continuum of care. Adherence to the $\mathrm{MOH}$ recommendation of ANC visit, which is at least 4 ANC visits at higher HFs, increased the likelihood of intensity of continuum of care. Despite the $\mathrm{MOH}$ recommendation, most women are following focused ANC visits in substandard health facilities. Moreover focused ANC visits at higher HFs didn't have better completion of $\mathrm{CoC}$ as compared to focused ANC visits at HPs. Intensity of $\mathrm{CoC}$ is also positively associated with exposure to HEP, knowledge of danger signs, and delivery of second youngest child at health facility. Women in the pastoralist areas were at a disadvantage compared to women in the agrarian in terms of the intensity of $\mathrm{CoC}$ which needs further consideration. To boost the uptake of all maternal health services, it is crucial to work on quality of health facilities to retain mothers in 
continuum of care, and promoting adherence to $\mathrm{MOH}$ recommendations of ANC visit. Promoting adherence of ANC visit may need upgrading the infrastructures of HPs and increasing access of health centers to the community. For the scientific community, it is good to investigate effect of quality of ANC at different level of HFs on completion of maternal health continuum of care.

\begin{abstract}
Abbreviations
ANC: Antenatal care; BIC: Bayesian information criterion; Cl: Confidence interval; HCs: Health centers; HEP: Health extension program; HEW: Health extension worker; HF: Health facility; HHs: Households; HP: Health post; IRR: Incidence rate ratio; MHS: Maternal health services; PNC: Postnatal care; PSM: Propensity Score Matching; RR: Rate ratio; SD: Standard deviation; TV: Television; WHO: World Health Organization; ZIP: Zero inflated Poisson.
\end{abstract}

\section{Acknowledgements}

We would like to express our gratitude to Bill and Melinda Gates foundation and MERQ Consultancy PLC for financing the study. We would also like to express our sincere thanks to PREPSS (https://sites.google.com/umich.edu/ prepss) for reviewing the article. The last we also pass our appreciation to data collectors, and study participants.

\section{Authors' contributions}

TLD, GM, AMT, YKA conceived the study, involved in the study design, data analysis, drafting the manuscript and critically reviewing the manuscript. HKK, WAG, MGJ and GMK involved in data analysis and critically reviewing the manuscript. All authors read and approved the final manuscript.

\section{Funding}

This study was done by MERQ Consultancy PLC, as part of the 2019 National Assessment of the Ethiopian Health Extension Program. MERQ has received funding for this assessment from the Bill \& Melinda Gates Foundation.

\section{Availability of the data and materials}

The datasets used during the current study is available from the corresponding author on reasonable request.

\section{Declarations}

\section{Ethics approval and consent to participate}

Institutional Review Board of Ethiopian Public Health Institute granted ethical clearance for the conduct of HEP assessment. Every tool used in the survey had appropriate information sheet and consent form that clearly describe the benefits and risk of participating in the assessment. The purpose and significance of the study were explained to each study participant and their consent was obtained before conducting interview. The respondents had full right to refuse to take part in the study, and this was clearly explained as part of information sheet. Confidentiality of information was assured. In addition, codes were used instead of participants' names.

\section{Competing interests}

The authors declare that have no competing interests.

\section{Consent for publication}

Not applicable.

\footnotetext{
Author details

${ }^{1}$ College of Medicine \& Health Science, School of Public Health, Hawassa University, Hawassa, Ethiopia. ${ }^{2}$ MERQ Consultancy PLC, Addis Ababa, Ethiopia. ${ }^{3}$ Aklilu Lemma Institute of Pathobiology, Addis Ababa University, Addis Ababa, Ethiopia. ${ }^{4}$ College of Medicine \& Health Science, Department of Midwifery, Wollega University, Nekemte, Ethiopia. ${ }^{5}$ International Institute for Primary Health Care - Ethiopia, Addis Ababa, Ethiopia. ${ }^{6}$ Institute of Health Science, Jimma University, Jimma, Ethiopia. ${ }^{7}$ Averting Maternal Death and Disability (AMDD), Columbia University, New York, NY, USA.
}

Received: 28 June 2021 Accepted: 13 October 2021

Published online: 06 November 2021

\section{References}

1. WHO. Strategies toward ending preventable maternal mortality (EPMM). Geneva: World Health OrganizatioN; 2015.

2. WHO, Unice, UNFPA, World Bank Group, UNPD. Trends in maternal mortality 2000 to 2017. Geneva: World Health Organization; 2019. p. 2019.

3. Kes A, Ogwang S, Pande RP, Douglas Z, Karuga R, Odhiambo FO, et al. The economic burden of maternal mortality on households: evidence from three sub-counties in rural western Kenya. Reprod Health. 2015;15:s3.

4. Moucheraud C, Worku A, Molla M, Finlay JE, Leaning J, Yamin AE. Consequences of maternal mortality on infant and child survival: a 25-year longitudinal analysis in Butajira Ethiopia (1987-2011). Reprod Health. 2015;15:s4.

5. Kadiyala S, Quisumbing A, Rogers B, Webb P. The impact of prime age adult mortality on child survival and growth in rural Ethiopia. World Dev. 2009;37(6):1116-28.

6. WHO. Progress towards the SDGs: A selection of data from World Health Statistics 2018. Geneva: WHO; 2018.

7. Ethiopia Ministry of Health. Envisioning Ethiopia's path towards universal health coverage through strengthening primary health care. 2015. http:// repository.iifphc.org/handle/123456789/402?show=full.

8. The Federal Democratic Republic of Ethiopia Ministry of Health. Ethiopia Health Sector Transformation Plan. Addis Ababa: FMOH; 2015.

9. WHO. WHO recommendations on maternal health: guidelines approved by the WHO Guidelines Review Committee. Geneva: WHO; 2017.

10. Adegboyega T, ba-Nguz E, Bahl R, Begkoyian G, Chitsike I, Chopra M, et al. Opportunities for Africa's Newborns. In: Lawn J, Kerber K, editors. The partnership for maternal, newborn and child health, 2010. https://www. who.int/pmnch/media/publications/oanfullreport.pdf.

11. Graft-Johnson Jd, Kerber K, Tinker A, Otchere S, Narayanan I, Shoo R, et al. The maternal, newborn, and child health: continuum of care. In: Oportunities for African newborns. Geneva; 2010. https://www.who.int/pmnch/ media/publications/oanfullreport.pdf.

12. Kerber KJ, de Graft-Johnson JE, Bhutta ZA, Okong P, Starrs A, Lawn JE. Continuum of care for maternal, newborn, and child health: from slogan to service delivery. Lancet. 2007;370(9595):1358-69.

13. WHO. RMNCH Continuum of care: Reproductive, maternal, newborn and child health. 2011. https://www.who.int/pmnch/about/continuum_of_ care/en/.

14. Tesfaye G, Loxton D, Chojenta C, Assefa N, Smith R. Magnitude, trends and causes of maternal mortality among reproductive aged women in Kersa health and demographic surveillance system, eastern Ethiopia. BMC Womens Health. 2018. https://doi.org/10.1186/s12905-018-0690-1.

15. Tessema GA, Laurence CO, Melaku YA, Misganaw A, Woldie SA, Hiruye $A$, et al. Trends and causes of maternal mortality in Ethiopia during 1990-2013: findings from the Global Burden of Diseases study 2013. BMC Public Health. 2017. https://doi.org/10.1186/s12889-017-4071-8.

16. Kikuchi K, Ansah EK, Okawa S, Enuameh Y, Yasuoka J, Nanishi K, et al. Effective linkages of continuum of care for improving neonatal, perinatal, and maternal mortality: a systematic review and metaanalysis. PLOS ONE. 2015;10:9.

17. Singh S, Darroch JE, Ashford LS. The costs and benefits of investing in sexual and reproductive health 2014. New York: Guttmacher Institute: 2014.

18. Central Statistical Agency (CSA) [Ethiopia] and ICF. Ethiopia demographic and health survey 2016. Addis Ababa, Ethiopia, and Rockville, Maryland, USA: CSA and ICF; 2016. p. 2016.

19. Ethiopian Public Health Institute (EPHI) [Ethiopia] and ICF. 2021. Ethiopia Mini Demographic and Health Survey 2019: Final Report. Rockville, Maryland, USA: EPHI and ICF.

20. Chaka EE, Parsaeian M, Majdzadeh R. Factors associated with the completion of the continuum of care for maternal, newborn, and child health services in Ethiopia. Multilevel model analysis. Int J Prev Med. 2019;10:136.

21. Emiru AA, Alene GD, Debelew GT. Women's retention on the continuum of maternal care pathway in west Gojjam zone, Ethiopia: multilevel analysis. BMC Pregnancy Childbirth. 2020;20(1):258. 
22. Defar A, Getachew T, Taye G, Tadele T, Getnet M, Shumet T, et al. Quality antenatal care services delivery at health facilities of Ethiopia, assessment of the structure/input of care setting. BMC Health Serv Res. 2020;20(1):485.

23. Medhanyie A, Spigt M, Dinant G, Blanco R. Knowledge and performance of the Ethiopian health extension workers on antenatal and delivery care: a cross-sectional study. Human Resour Health. 2012;10:44.

24. Ethiopian Public Health Institute (EPHI). Ethiopia Services Availability and Readiness Assessment (SARA). Addis Ababa: Ethiopian Public Health Institute (EPHI) and $\mathrm{MOH} ; 2018$.

25. Asratie MH, Muche AA, Geremew AB. Completion of maternity continuum of care among women in the post-partum period: magnitude and associated factors in the northwest, Ethiopia. PLOS ONE. 2020;15(8):e0237980.

26. Ministry of Health - Ethiopia. Essential health services package of Ethiopia. Addis Ababa: $\mathrm{FMOH} ; 2019$.

27. Tegegne TK, Chojenta C, Getachew T, Smith R, Loxton D. Antenatal care use in Ethiopia: a spatial and multilevel analysis. BMC Pregnancy Childbirth. 2019;19:399.

28. Haile D, Kondale M, Andarge E, Tunje A, Fikadu T, Boti N. Level of completion along continuum of care for maternal and newborn health services and factors associated with it among women in Arba Minch Zuria woreda, Gamo zone, Southern Ethiopia: A community based crosssectional study. PLOS ONE. 2020;15(6):e0221670.

29. Teklu AM, Alemayehu YK, Medhin G, Fentaye FW, Dadi TL, Tsehay YE, et al. National assessment of the ethiopian health extension program. Addis Ababa: MERQ Consultancy PLC; 2020.

30. Central Statistical Agency (CSA) [Ethiopia]. Population Projections for Ethiopia 2007-2037. Addis Ababa: Population Census Commission; 2013.

31. Federal Ministry of Health [Ethiopia]. Health and Health-Related Indicators 2019. https://e-library.moh.gov.et/library/wp-content/uploads/2021/ 07/Health-and-Health-Related-Indicators-2011.pdf.

32. Karen Glanz BKR, and K. Viswanath. Health behavior and health education: theory, research, and practice, 4th ed; 2008. ISBN:978-0-7879-9614-7.

33. Hilbe JM. Modeling count data by New York. NY: Cambridge University Press; 2014

34. Muluneh AG, Kassa GM, Alemayehu GA, Merid MW. High dropout rate from maternity continuum of care after antenatal care booking and its associated factors among reproductive age women in Ethiopia, Evidence from Demographic and Health Survey 2016. PLoS ONE. 2020;15(6):e0234741.

35. Medhanyie A, Spigt M, Kifle Y, Schaay N, Sanders D, Blanco R, et al. The role of health extension workers in improving utilization of maternal health services in rural areas in Ethiopia: a cross sectional study. BMC Health Serv Res. 2012. https://doi.org/10.1186/1472-6963-12-352.

36. Ethiopian Standard. Health post-requirements. Addis Ababa: Ethiopian Standard and $\mathrm{MOH} ; 2012$

37. Jalu MT, Ahmed A, Hashi A, Tekilu A. Exploring barriers to reproductive, maternal, child and neonatal (RMNCH) health-seeking behaviors in Somali region, Ethiopia. PLoS ONE. 2019;14(3):e0212227.

38. Alemayehu M, Gebrehiwot TG, Medhanyie AA, Desta A, Alemu T, Abrha A, et al. Utilization and factors associated with antenatal, delivery and postnatal Care Services in Tigray Region, Ethiopia: a community-based cross-sectional study. BMC Pregnancy Childbirth. 2020;20(1):334.

39. Chaka EE, Abdurahman AA, Nedjat S, Majdzadeh R. Utilization and determinants of postnatal care services in ethiopia: a systematic review and meta-analysis. Ethiop J Health Sci. 2019;29(1):935-44.

40. Singh K, Story WT, Moran AC. Assessing the continuum of care pathway for maternal health in South Asia and Sub-Saharan Africa. Matern Child Health J. 2016;20(2):281-9.

41. Federal Democratic Republic of Ethiopia Ministry of Health. Antenatal care, Part 2: Blended learning module for the health extension program. The Open University. https://www.open.edu/openlearncreate/mod/ oucontent/view.php?id=27.

42. Gebrehiwot TG, San Sebastian M, Edin K, Goicolea I. The health extension program and its association with change in utilization of selected maternal health services in Tigray Region, Ethiopia: a segmented linear regression analysis. PLoS ONE. 2015;10(7):e0131195.

43. Workie NW, Ramana GN. The health extension program in Ethiopia. Washington: The World Bank; 2013.

44. Atnafu A, Kebede A, Misganaw B, Teshome DF, Biks GA, Demissie GD, et al. Determinants of the continuum of maternal healthcare services in northwest Ethiopia: findings from the primary health care project. J Pregnancy. 2020:2020:4318197.

45. Dubale T, Mariam DH. Determinants of conventional health service utilization among pastoralists in northeast Ethiopia. Ethiop J Health Dev. 2007;21:142-7

46. Ahmed M, Demissie M, Worku A, Abrha A, Berhane Y. Socio-cultural factors favoring home delivery in Afar pastoral community, northeast Ethiopia: a qualitative study. Reprod Health. 2019;16(1):171.

\section{Publisher's Note}

Springer Nature remains neutral with regard to jurisdictional claims in published maps and institutional affiliations.
Ready to submit your research? Choose BMC and benefit from:

- fast, convenient online submission

- thorough peer review by experienced researchers in your field

- rapid publication on acceptance

- support for research data, including large and complex data types

- gold Open Access which fosters wider collaboration and increased citations

- maximum visibility for your research: over $100 \mathrm{M}$ website views per year

At $\mathrm{BMC}$, research is always in progress.

Learn more biomedcentral.com/submissions 